\title{
Memorias y olvidos en el marco del posconflicto peruano
}

Reseña: Milton, C. (2018), Conflicted Memory. Military Cultural Interventions and the Human Rights Era in Perú. Madison: University of Wisconsin Press.

\section{María Helena Carbonell Yánez *}

6 6La memoria es frágil" dice la sabiduría popular y, cuando se trata de eventos que impactan negativamente a una sociedad, esto es aún más cierto. El olvido se vuelve una herramienta para desconocer hechos que la marcaron ya sea por no querer recordar el dolor o como mecanismo para mantener o repetir los mismos hechos. Frente a esto, el recobrar lo sucedido se transforma en una lucha constante de diversos sectores sociales.

A pesar de su importancia, el interés académico por la memoria es relativamente nuevo. Esta es una de las razones por las cuales el libro "Conflicted Memory. Military Cultural Interventions and the Human Rights Era in Perú" de Cynthia E. Milton es un aporte fundamental para esta rama de estudio. El aporte de Milton recibió una mención de honor en el marco del Premio LASA 2020, en la categoría "Historia reciente y Memoria”. Esta mención de honor se adecúa perfectamente al objetivo de esta sección de LASA ya que la autora brinda un estudio sobre el pasado reciente peruano, así como su abuso, dentro del contexto de la época del conflicto armado y años posteriores.

El elemento central del estudio de Milton es la memoria, entendida como el escenario en el que se concretan pugnas de poder entre diversos actores. Sobre los usos políticos de la memoria, los argumentos de la autora

\footnotetext{
* Abogada, PhD. en Derecho por la Universidad Andina Simón Bolívar. Docente Universitaria. Correo: maria.helena. carbonell@gmail.com
} 
coinciden con los planteados, por ejemplo, por Katherine Hite y su estudio sobre el "Ojo que llora" (de Lika Mutual), en Perú. Esta autora nos hace un recuento de los obstáculos que se debieron sortear para mantener la obra, demostrando lo que Milton plantea, de manera más general, haciendo referencia a otros procesos de posconflicto.

Dentro de esta escena, la memorialización y el reconocimiento de los hechos cobran vital importancia. Estos procesos de memorialización incluyen la construcción de monumentos, museos, sitios históricos, entre otros. Perú no es la excepción: frente a las secuelas del conflicto, el recordar ha sido importante. Sin embargo, en el caso peruano, tales procesos parten de la idea de una verdad histórica basada en una memoria construida en una época posconflicto principalmente por el Informe de la Comisión de la Verdad y Reconciliación.

Conflicted Memory aborda la compleja relación entre la arista individual y la social de la memoria, dejando de lado la dicotomía entre versión oficial y versión no oficial de los hechos. La autora plantea que el "lenguaje de los derechos humanos" ha sido usado por todos los sectores para defender su posición relativa a los hechos y responsables del conflicto. De esta manera, reconoce una miríada de actores intervinientes en la época del conflicto interno del Perú (1980 - 2000).

Tal como lo mencionó el Informe de la Comisión de la Verdad y Reconciliación, un alto porcentaje de los perpetradores de violaciones de derechos humanos pertenece a las fuerzas de seguridad del Estado, incluidas las Fuerzas Armadas. Frente a esto, una vez que se entregó dicho Informe, se intentó llevar a cabo un proceso de "saneamiento" de la imagen pública de este cuerpo de seguridad que fue (o quizás sigue siendo) bastante negativa. Uno de los mecanismos usados para tal "saneamiento" es la publicación de libros que brindan una versión alterna de los hechos aceptados como 
verdad oficial. Mediante una exhaustiva revisión de la literatura, la autora nos presenta un estudio crítico de los más famosos intentos de "arreglar" la narrativa oficial a través de una narrativa alternativa proveniente de sectores afines a las Fuerzas Armadas.

Pero la literatura no es el único enfoque de Milton. Dentro de los procesos de memorialización, la autora pone un especial interés en los museos y su rol en la presentación de los hechos como los ven los actores involucrados. Ella describe, de una manera profunda, su visita a tres museos que buscan visibilizar la "otra" versión de los hechos. Entre éstos, el museo de la Dirección contra el Terrorismo (DIRCOTE) y la Unidad de la Policía Nacional contra el Terrorismo, y el monumento para los Héroes of Chavín de Huántar de las Fuerzas Armadas, presentan una memoria centrada en los "otros" (no las "tradicionales víctimas del conflicto"). Mediante su recuento del proceso de creación del Lugar de la Memoria, la Tolerancia y la Inclusión Social (LUM), Milton tiene cono elemento central en su construcción la participación de aquellos que intervinieron en los hechos ocurridos. Siguiendo este planteamiento la autora se enfoca en las posturas de los representantes de las Fuerzas Armadas y plasma sus intrincaciones en estos procesos.

Finalmente, Milton discute una de las herramientas más comunes para olvidar lo sucedido desde la memoria social o colectiva: la censura. Centrada, inicialmente en las caricatura "Iwo Jima" de Piero Quijano y la obra de teatro "La Cautiva", ella aborda lo literario (en el teatro y el humor en la caricatura) como una herramienta de combate frente a gobiernos de tinte autoritario, especialmente en momentos de justicia transicional. Cabe decir que tal aproximación no es útil sólo en transiciones, sino que también nos permite reflexionar lo que sucede durante gobiernos calificados como democráticos. 
La censura es una herramienta usada para el proceso de "saneamiento" de la imagen negativa de las Fuerzas Armadas. Posteriormente al conflicto, mediante el uso de las instituciones democráticas, se puede ejercer un tipo de censura que afecta la versión "oficial" de los hechos. Esta censura, se argumenta, puede llevársela a cabo mediante una crítica frontal, formas más sutiles o, incluso, a través del Derecho Penal (por ejemplo, se alegaba que el guión de "La cautiva" constituía "apología el terrorismo", un delito que podía acarrear entre 6 a 12 años de prisión) como rezago del gobierno autoritario de Fujimori en épocas de un gobierno democrático.

Otro elemento que es necesario abordar es ver la censura como un obstáculo para la reparación de las víctimas de violaciones de derechos humanos. Especialmente en lo que tiene que ver con las medidas de satisfacción ordenadas a nivel nacional o internacional (por ejemplo, por las Comisión y la Corte Interamericanas de Derechos Humanos). Esta modalidad de reparación incluye, entre otras, las disculpas públicas o el llevar a cabo procesos de memorialización que pueden materializarse de diversas maneras.

El trabajo de Cynthia Milton, sobre la utilización de estos procesos de construcción y deconstrucción de la memoria coincide con los trabajos de Richard Cox, en lo que se refiere a la necesidad de entender la relación entre la guerra y la memoria a través de la construcción de los hechos. Sobre este punto, hay que reconocer que uno de los aporte de Milton es brindar un panorama profundo sobre los intentos, desde las Fuerzas Armadas, de cuestionar la visión oficial de los hechos. Ella parece reconocer que ésta es una lucha constante sin que se vea un fin cercano ya que los actores continúan su búsqueda de la verdad, reparación y justicia, cada uno desde su memoria de los hechos. 